\title{
Escritura en el primer ciclo: entre concepciones y representaciones sociales
}

\author{
Writing in the First Cycle; between Conceptions and Social Representations
}

Andrea Ruiz Gómez*

Recibido: 16 de agosto de 2012

Aceptado: 17 de septiembre de 2012

\section{Resumen}

La enseñanza de la escritura durante el primer ciclo favorece las prácticas centradas en aspectos perceptivos, motrices y prescriptivos. Estas prácticas están sustentadas en concepciones de escritura de los docentes que no se investigan ni se transforman. Tampoco se reconocen las representaciones sociales que sobre la escritura construyen los niños. Este artículo se propone dar cuenta de las concepciones de escritura de los docentes y de las representaciones sociales de escritura de niños de primer ciclo, encontradas en la investigación "La construcción de la escritura en el primer ciclo: entre las concepciones de los docentes y las representaciones sociales de los niños", desarrollada en tres colegios de Bogotá, a partir del diseño metodológico de la teoría fundamentada.

Palabras clave: escritura, primer ciclo, concepciones, concepciones de escritura, representaciones sociales de la escritura.

\section{Abstract}

The teaching of writing during the first cycle promotes practices focusing on perceptual, motor, and prescriptive aspects. These practices are grounded from the teachers writing conceptions; which are not investigated nor transformed. Moreover, the social representations built on writing from children are not recognized. Therefore, the main objective of this article is to present the results of the research "The construction of the writing in the first cycle: between the teachers conceptions and social representations of children"; it was developed between three schools in Bogotá and methodological design used was grounded theory.

Key words: writing, first grades, conceptions, writing conceptions, social representations of writing.

* Máster en Pedagogía de la Lengua Materna, Universidad Distrital Francisco José de Caldas. Docente de preescolar en el colegio Los Nogales. Correo electrónico: aruiz@nogales.edu.co 


\section{Introducción}

La construcción de la escritura en el primer ciclo es un asunto que, pese a las innovaciones y propuestas de algunos grupos de investigación y de valiosas experiencias educativas, no ha logrado transformar con toda su fuerza las prácticas de enseñanza de gran número de docentes. En este primer ciclo, culturalmente asumido como el nivel escolar responsable de que los niños accedan a la "escritura formal", es en el que se evidencia menos innovación y transformación de dichas prácticas, crean menor impacto las propuestas investigativas, se sigue considerando la escritura como una habilidad perceptiva y motriz reducida a la enseñanza y al uso prescriptivo del alfabeto, y en el que una concepción de escritura como construcción social y cultural todavía está en mora.

Esta situación tan poco optimista responde a concepciones de la escritura construidas por los profesores, a partir de su experiencia, de sus creencias, de su conocimiento teórico, pero también empírico, de sus afectos, de sus ideas, en fin, de su propia historia. Las concepciones, difíciles de transformar, están fuertemente arraigadas e involucran, además de la esfera del conocimiento, la esfera afectiva.

Por otro lado, están las representaciones sociales sobre la escritura que construyen los niños a partir de lo que observan, escuchan y elaboran en sus contextos más cercanos; y de lo que otros sujetos (miembros de la familia y maestros, especialmente) les "enseñan", pero que no siempre son reconocidas por los docentes.

Concepciones de los docentes y representaciones sociales de los niños son dos conocimientos que, aunque presentes en el aula, no se encuentran, no se reconocen $y$, por supuesto, no convergen para favorecer la escritura como una construcción social y cultural que debe darse desde el inicio de la escolaridad. Todo esto se evidencia en los resultados de la investigación titulada "La construcción de la escritura en el primer ciclo: entre las concepciones de los docentes y las representaciones sociales de los niños", realizada en el marco de la Maestría en Pedagogía de la Lengua Materna de la Universidad Distrital.

Concepciones, representaciones sociales y escritura son entonces elementos que requieren mayor explicación.

\section{Concepciones}

Elinterés por las concepciones de los docentes estáenmarcado dentro del paradigma del "pensamiento del profesor", campo en el que autores como Clark (1978), Berliner (1984), Doyle (1985) y otros citados por Marcelo (1987) conciben al profesor como un agente activo, cuyos conocimientos implícitos y explícitos influyen en sus acciones en el aula. Esto en contraposición al paradigma proceso-producto, reinante en las investigaciones sobre educación que había hasta ese momento, con el objetivo de identificar las conductas de los docentes que lograban un mejor rendimiento de los alumnos y negaban al docente como sujeto de conocimiento. En este paradigma del pensamiento del profesor, este se sitúa como un sujeto reflexivo, racional, que toma decisiones, emite juicios, tiene creencias y genera rutinas propias de su desarrollo profesional. Un sujeto cuyos pensamientos influyen sustancialmente en su conducta, e incluso la determinan, y median así significativamente sus acciones en el aula (Clark y Peterson, 1990, como se cita en Perafán, 2004) y sus concepciones.

Las concepciones implican, entonces, una reflexión activa y constructiva por parte del profesor que le permiten evolucionar hacia una conceptualización más adecuada para enfrentar las situaciones nuevas que se le presentan en el aula. Pero estas mismas concepciones tienen otras implicaciones: escapan al propio control, tienden a bloquear los cambios en el dominio de lo concreto, favorecen cierta disociación 
entre el discurso pedagógico y la intervención docente y guardan relación con la estructura del puesto de trabajo, en la que el tiempo laboral es fundamentalmente para intervenir y no para reflexionar (Porlán y Rivero, 1998).

A esto se suma que las concepciones de los docentes permanecen implícitas, difieren del conocimiento científico y tienen una fuerte influencia de aspectos afectivos y valorativos, lo que las hace difíciles de transformar, como lo expresan Morales y Bojacá (2002). Esta es la razón por la cual las jornadas de capacitación, los cursos remediales y los programas de actualización, cuyo objetivo es “informar" o "actualizar" a los docentes sobre las nuevas perspectivas en didáctica de la escritura, no son suficientes para transformar o innovar las prácticas de enseñanza de la escritura en las escuelas.

Es necesario reconocer las concepciones como elementos importantes, no solo en el proceso de enseñanza, sino como aspectos que posibilitan la indagación y la reflexión, que requieren una investigación permanente y que son determinantes en la transformación de la educación. Como bien lo expresa Arbeláez (2004):

En la medida en que el docente es consciente de la naturaleza de sus conocimientos respecto a la función educativa y la enseñanza de su asignatura, entra en el camino de las innovaciones posibles, de los conocimientos y las acciones profesionales. El reconocimiento de su propio saber, como una especie de autoexamen, le permite al profesor la elaboración de nuevas concepciones, en una tendencia evolutiva de construcción de nuevos significados en torno a la problemática educativa en la que se halla inmerso, que lo conduce a una clara y responsable conciencia de las decisiones que tome en su práctica cotidiana, y en general en su vida profesional. (p. 68)

\section{Representaciones sociales}

Aunque las representaciones sociales pertenecen al campo de las ciencias sociales, proporcionan un marco interesante para develar de qué manera los niños de primer ciclo se representan socialmente la escritura. Las representaciones sociales se refieren al conocimiento del sentido común que se pone a disposición en la experiencia cotidiana, y sirven de guía para la acción y como instrumento para leer la realidad. Son sistemas de significaciones que permiten a los sujetos interpretar el curso de los acontecimientos y las relaciones sociales. Son forjadas en la interacción y en el contacto con los discursos que circulan en el espacio público, están inscritas en el lenguaje y las prácticas, y funcionan como un lenguaje en razón de su función simbólica y de los marcos que proporcionan para codificar y categorizar lo que compone el universo de la vida (Jodelet y Guerrero, 2000).

Cuando un niño está aprendiendo a escribir, requiere de la ayuda de los otros (profesores y pares), pero también de un trabajo individual, porque la construcción escritural la realiza finalmente el propio individuo (Ramírez y Gómez, 2000). De esta manera, sus ideas o representaciones no son solo el reflejo del discurso de los adultos, sino que son elaboraciones propias de los niños construidas a partir de lo que observan en sus contextos, de lo que les "enseñan" esos otros, de informaciones y de opciones que les brinda el medio, por nombrar solo algunos. Las representaciones sociales se producen, se recrean y se modifican en las interacciones y las prácticas sociales (Castorina y Kaplan, 2003) que se promueven en la escuela, con pares y maestros, pero también en casa y en el contexto inmediato.

Las representaciones sociales tienen que ver con la manera como los niños aprehenden los acontecimientos de la vida diaria, las informaciones del medio ambiente y de las personas del entorno próximo o lejano. Este aprendizaje se construye a través de experiencias, pero también de informaciones, conocimientos y modelos de pensamiento que se reciben 
y se transmiten a través de la tradición, la educación y la comunicación social (Jodelet, 1986).

\section{Escritura}

Como todo aprendizaje, el de la escritura es un hecho social que, partiendo de los postulados de Vygotsky (1979), primero se realiza a nivel social y luego, mediante el proceso de internalización, se efectúa de manera individual. El mismo autor insiste en que el aprendizaje de la escritura no es un dominio puramente externo, mecánico, dado desde fuera, sino que se constituye en un proceso complejo, en una función psicológica superior que supone grandes cambios en todos los ámbitos y abre el espectro en los campos cultural y social (Vygotsky 1995). Por eso no puede reducirse al aprendizaje y uso del alfabeto.

Tolchinsky (1993) expresa que las condiciones que permitieron el surgimiento de la escritura están social e históricamente determinadas, y es también a nivel social que la escritura se construye, pues es en las comunidades donde cumple múltiples funciones. Precisamente esa multiplicidad de funciones promueve el desarrollo hacia niveles más altos, hacia formas superiores de pensamiento. Sin embargo, en la escuela tienden a favorecerse las acciones de tipo formal e instrumental (focalizando la atención en los trazos y el aprendizaje de las letras), y se deja de lado la posibilidad de construir conocimiento social y cultural con sentido y significado.

La escritura es una actividad que ha posibilitado la construcción y la transformación de la cultura y de la sociedad y, en consecuencia, del propio ser humano. Los procesos sociales que se dan por medio de ella suceden exteriormente y entre individuos que se comunican y se relacionan, y que construyen así cultura y conocimiento social (Pittard y Martlew, 2000). La escritura como construcción social involucra varios elementos (el contexto, los factores culturales, los factores sociales, la caja de herramientas de la que habla Bruner (1997), cuyas relaciones determinan las concepciones de los docentes, las representaciones sociales y los usos de la escritura que los niños construyen, e influyen en la manera como esta se propicia en el aula y en la vida en general.

La escritura se constituye en una construcción sociocultural cuyo desarrollo se halla íntimamente vinculado con los seres humanos, sus pautas de comunicación y el uso que se hace de ella para la mediación de las actividades de la vida cotidiana. El lenguaje, y para este caso más específicamente la escritura, encarna los lazos que unen a los seres humanos entre sí, con su cultura y con su pensamiento (Vygotsky, 1978, como se cita en Moll, 1993). La escritura se aprende socialmente y es socialmente como se desarrolla, en el uso real que se le da en los diferentes contextos, desde la mediación que realiza entre el sujeto y la vida humana como una acción con sentido, en la que se tienen en cuenta sus procesos interactivos y enunciativos (Morales y Bojacá, 2002).

En la investigación realizada, este enfoque de escritura no resulta fácil de encontrar en las aulas, y menos aún en los primeros grados de escolaridad, en los que escribir se reduce a un ejercicio meramente instrumental y perceptivo de estudio del alfabeto.

\section{Metodología}

Para determinar cuáles son las concepciones de escritura que prevalecen en los docentes de primer ciclo y las representaciones sociales de escritura, se contó con la participación de 65 niños y 12 maestros de tres colegios de Bogotá, a través de entrevistas y observaciones de clases. La información obtenida se constituyó en un buen corpus para ser analizado a través de la teoría fundamentada en datos, estrategia de investigación cualitativa por medio de la cual se busca generar teoría sustantiva de naturaleza local, que se relaciona con una situación y un contexto es- 
pecíficos y aporta nuevas visiones sobre un fenómeno particular (Hernández, Fernández y Baptista, 2008).

Para lograr una teoría fundamentada en datos se requiere desarrollar un conjunto de pasos que favorecen la codificación y el análisis exhaustivo de la información: codificación abierta, codificación axial y codificación selectiva. Estos pasos, no necesariamente consecutivos, garantizan la construcción de una buena teoría (Strauss y Corbin, 2002).

\section{Resultados}

Se presentan a continuación algunos de los resultados más relevantes, obtenidos en los diferentes momentos de codificación:

1. Concepciones de escritura de los docentes de primer ciclo.

2. Representaciones sociales de lo que es la escritura para los niños de primer ciclo.

3. Representaciones sociales de la importancia social y los usos que los niños le dan a la escritura.

\section{Concepciones de escritura de los docentes de primer ciclo}

La tabla 1 presenta las concepciones de escritura de los docentes entrevistados, iniciando con las de mayor número de respuestas.

Tabla 1. Concepciones de escritura de docentes de primer ciclo

\begin{tabular}{|l|l|}
\hline \multicolumn{1}{|c|}{ Categorías generales } & \multicolumn{1}{c|}{ Subcategorías } \\
\hline \multirow{4}{*}{$\begin{array}{l}\text { Escritura como código } \\
\text { alfabético. }\end{array}$} & $\begin{array}{l}\text { Escritura como cono- } \\
\text { cimiento del código } \\
\text { alfabético. }\end{array}$ \\
& Escritura solo de palabras \\
& y oraciones. \\
& Escritura de párrafo. \\
& Escritura fonema-sonido. \\
\hline
\end{tabular}

\begin{tabular}{|l|l|}
\hline \multicolumn{1}{|c|}{ Categorías generales } & \multicolumn{1}{c|}{ Subcategorías } \\
\hline Escritura como copia. & \\
\hline $\begin{array}{l}\text { Escritura como habilidad } \\
\text { motriz. }\end{array}$ & \\
\hline $\begin{array}{l}\text { Escritura como actividad } \\
\text { espontánea. }\end{array}$ & $\begin{array}{l}\text { Escritura como medio } \\
\text { de expresión y de } \\
\text { comunicación. }\end{array}$ \\
\hline $\begin{array}{l}\text { Escritura como proceso } \\
\text { por etapas. }\end{array}$ & \\
\hline $\begin{array}{l}\text { Escritura como un cono- } \\
\text { cimiento para ser usado } \\
\text { más adelante. }\end{array}$ & \\
\hline $\begin{array}{l}\text { Escritura como acto } \\
\text { consciente. }\end{array}$ & \\
\hline
\end{tabular}

Fuente: Elaboración propia.

La concepción de escritura privilegiada por los docentes es la que la considera como el aprendizaje y uso del código alfabético que, una vez aprendido, servirá para la posterior conformación de palabras, oraciones y párrafos. Como consecuencia las concepciones de la escritura como copia y como habilidad motriz, favorecen las actividades de aprestamiento, trazo adecuado de las letras, manejo del renglón y planas. Se observa, entonces, que las prácticas de enseñanza de la escritura no han logrado modificarse, porque tampoco lo han hecho las concepciones de los docentes, y la escritura sigue considerándose en el primer ciclo como una habilidad motriz y prescriptiva que se encarga solo del estudio de las letras. Como afirma Vygotsky (1979), se enseña el alfabeto pero no la escritura.

Otra de las concepciones que cabe resaltar es la de la escritura como actividad espontánea. Los profesores afirman que los niños usan la escritura para expresar o comunicar sentimientos y emociones de manera esporádica, pero ninguno la relaciona con una necesidad real intencional que requiere planeación y un propósito auténtico. 
Como respuestas menos frecuentes en los maestros se encuentran la escritura como proceso por etapas y la escritura como un conocimiento para ser usado más adelante. La escritura como proceso por etapas se refiere a los momentos de la adquisición del código alfabético que nombran los profesores: primero las vocales, luego las consonantes, las combinaciones, la escritura de palabras, de frases y, finalmente, de párrafos. En la concepción de la escritura como un conocimiento para ser usado más adelante se evidencia que los profesores comprenden la escritura como un acto complejo que cumple múltiples funciones y responde a diversos objetivos de tipo cognitivo, social y cultural, que inicia en el primer ciclo e incluso antes; pero para la mayoría de profesores entrevistados la "escritura real", con un objetivo claro, se realiza en la primaria, no antes.

Por último, se encuentra la concepción de la escritura como acto consciente, que es alentadora en el sentido de incluir a quien escribe, o a quien está aprendiendo a escribir (el niño de primer ciclo), como un actor que le concede una intencionalidad, una función social y que implica procesos reflexivos. Sin embargo, solo dos de los trece profesores entrevistados se refirieron a ella.

Aunque los profesores entrevistados expresan la necesidad de dejar a un lado las prácticas tradicionales de enseñanza de la escritura, es importante recordar que, mientras las concepciones centradas en una enseñanza fragmentada, en aspectos motrices y perceptuales no sean objeto de reflexión y de transformación, es improbable lograr cambios sustanciales en la construcción de la escritura como un bien social y cultural, y reconocer las representaciones sociales que construyen los niños como un punto de partida importante para la construcción de este conocimiento.

\section{Representaciones sociales de lo que es la escritura para los niños de primer ciclo}

La siguiente tabla presenta las categorías y subcategorías que surgen de las respuestas de los niños y las niñas frente a lo que ellos consideran como escritura. Al igual que el anterior, se inicia con las que tienen mayor número de respuestas.

Tabla 2. Representaciones sociales de lo que es la escritura para los niños de primer ciclo

\begin{tabular}{|l|l|}
\hline \multicolumn{1}{|c|}{ Categorías } & \multicolumn{1}{c|}{ Subcategorías } \\
\hline $\begin{array}{l}\text { La escritura como el acto } \\
\text { de copiar de otros. }\end{array}$ & $\begin{array}{l}\text { Enseñanza del trazo. } \\
\text { Calidad y belleza de la } \\
\text { letra. } \\
\text { La escritura como } \\
\text { habilidad motriz. } \\
\text { Velocidad en la escritura. } \\
\text { Cantidad. }\end{array}$ \\
\hline $\begin{array}{l}\text { La escritura como } \\
\text { aprendizaje del código } \\
\text { alfabético. }\end{array}$ & $\begin{array}{l}\text { Aprendizaje de las letras. } \\
\text { Escritura de palabras. } \\
\text { Escritura de frases. } \\
\text { Escritura como algo } \\
\text { permanente. }\end{array}$ \\
\hline $\begin{array}{l}\text { La escritura como acto de } \\
\text { memorización. }\end{array}$ & \\
\hline La escritura como dibujo. & \\
\hline
\end{tabular}

Fuente: Elaboración propia.

Las representaciones sociales de escritura elaboradas por los niños están relacionadas con la vida escolar especialmente. Esto se entiende porque la escuela constituye el contexto donde ellos reciben gran cantidad de información, que no solo copian o repiten sino que reelaboran; es la escuela el medio en el que permanentemente están aprehendiendo. Por otro lado, las letras son el aspecto "visible" de la escritura y los niños también les asignan un valor 
importante en sus representaciones sociales. Es así que la escritura como copia, como habilidad motriz y como aprendizaje del código alfabético, que aparecen como concepciones importantes de los docentes, coinciden con las representaciones sociales de escritura más nombradas por los niños.

"Escribir es copiar", pero la copia no es entendida con un objetivo dinámico, como una actividad que resulta después de una producción individual o colectiva, ni de capturar o registrar algún tipo de información que se considere importante, sino como la simple transcripción, en un ejercicio en el que las palabras o frases son dadas por otros (adultos). Calcar, imitar y remedar son sinónimos que utilizan los niños para explicar una de las maneras de comprender la escritura en la escuela. Este "copiar" se manifiesta en oposición a la producción escrita que no aparece en ninguna de las respuestas de los niños.

Además de la copia, una representación social que los niños han construido está relacionada con el reconocimiento de las acciones físicas que se dan en la actividad de escribir. Se contempla, así, el desarrollo de habilidades manuales como la coordinación motriz, la precisión de los rasgos, el manejo del renglón, la realización de letra cursiva o script, la velocidad, la cantidad de escritura y el aspecto estético. Además del trazo adecuado, los niños hacen una obvia referencia al aprendizaje de las letras y a la combinación de estas para formar palabras. Si los profesores expresan permanentemente que su objetivo es enseñar las letras para que los niños aprendan a escribir, es de esperarse que los niños hagan una referencia permanente al mismo hecho.

Otras representaciones sociales de los niños se refieren a la escritura como acto de memorización y como dibujo. Los niños señalan que es necesario conocer las letras o adquirir las herramientas necesarias para escribir y que, una vez que las han "memorizado", pueden usarlas para escribir lo que se necesite. Por otro lado, los niños más pequeños no diferencian totalmente la escritura de los dibujos. Esto se puede interpretar por la relación que ellos hacen entre la escritura y los afiches, avisos y otras manifestaciones publicitarias a las que tienen acceso, en las que se emplean diferentes textos gráficos y escritos. Es importante anotar que el dibujo aparece como un relato gráfico desde la prehistoria de la escritura presentada por Vygotsky (1931). El dibujo precede a la escritura, como un simbolismo primario.

\section{Representaciones sociales de la importancia social y usos que los niños le otorgan a la escritura}

Además de las representaciones sociales asociadas especialmente a lo que los niños entienden por escritura, ellos reconocen otros usos y funciones que se dan en la cotidianidad, dentro y fuera de la escuela, como lo muestra la tabla 3.

Tabla 3. Representaciones sociales sobre los usos y funciones que los niños le otorgan a la escritura

\begin{tabular}{|c|c|}
\hline Categoría & Subcategorías \\
\hline $\begin{array}{l}\text { Escritura con función } \\
\text { escolar. }\end{array}$ & $\begin{array}{l}\text { Para aprender a escribir. } \\
\text { Para hacer tareas. } \\
\text { Para ir a la universidad. } \\
\text { Para ser evaluados. } \\
\text { Como requisito para pasar } \\
\text { el año. } \\
\text { Para enseñar a otros. }\end{array}$ \\
\hline Escritura como deber. & $\begin{array}{l}\text { Como obligación. } \\
\text { Como acción defensiva. }\end{array}$ \\
\hline $\begin{array}{l}\text { Escritura como medio de } \\
\text { expresión. }\end{array}$ & $\begin{array}{l}\text { Como medio } \\
\text { de expresión afectiva. } \\
\text { Como medio } \\
\text { de expresión lúdica. }\end{array}$ \\
\hline
\end{tabular}

continúa 


\begin{tabular}{|l|l|}
\hline \multicolumn{1}{|c|}{ Categoría } & \multicolumn{1}{c|}{ Subcategorías } \\
\hline $\begin{array}{l}\text { Escritura como medio de } \\
\text { comunicación. }\end{array}$ & $\begin{array}{l}\text { Para comunicar. } \\
\text { Para solicitar ayuda. }\end{array}$ \\
\hline $\begin{array}{l}\text { Escritura como un medio } \\
\text { para brindar ayuda. }\end{array}$ & \\
\hline $\begin{array}{l}\text { Escritura como instru- } \\
\text { mento de registro. }\end{array}$ & \\
\hline $\begin{array}{l}\text { Escritura como compe- } \\
\text { tencia laboral. }\end{array}$ \\
\hline
\end{tabular}

Fuente: Elaboración propia.

En las representaciones sociales de escritura de los niños, predominan las experiencias de la vida escolar: se aprende a escribir para aprender, para hacer tareas, para ir a la universidad, para ser evaluados, para pasar el año, para enseñar a otros, etc. Estos aspectos cobran mucha fuerza porque, como se expresaba anteriormente, la escuela es el contexto social más importante para ellos, donde realizan "prácticas" que los acercan al uso de la escritura.

Lo irónico es que, siendo la escuela una de las instituciones sociales por excelencia donde se posibilita a los niños el encuentro con los otros desde distintos medios como el juego, la interacción, la conversación, el intercambio y la construcción de conocimiento, no fomente la construcción social de la escritura. Por un lado, privilegia especialmente prácticas individuales de mecanización de la escritura, en lugar de favorecerla como una construcción social; y, por otro, se desaprovecha el papel de la escuela como dinamizadora de una comunidad y de la función que cumple la escritura, pues no alcanza a trascender las paredes de dicha institución para comunicar, expresar y transformar.

Pese a lo anterior, otras representaciones sociales de escritura elaboradas por los niños se desarrollan especialmente fuera de esta institución (escolar) y evidencian la manera sutil como ellos separan la escritura de carácter escolar (y lo que esta conlleva: las planas, las tareas, la copia, etc.) y la escritura de carácter social que usan fuera de la escuela, en la que el objetivo pasa a ser el mensaje, la intención comunicativa. Hay una necesidad real de escribir un texto específico para "alguien" específico.

En estas representaciones, la escritura adquiere el carácter de una herramienta que posibilita el establecimiento de relaciones e interacciones entre sujetos pertenecientes a una misma familia o comunidad. Se reconoce como un medio de expresión afectiva, por medio de tarjetas y cartas que escriben para sus familiares, y lúdico, por la posibilidad de creación de cuentos e historietas. También, como un medio de comunicación que los niños usan, o ven que se usa, para comunicar, para brindar información, notas, informes de trabajo, etc. Además se reconoce como una manera de brindar ayuda a otros o de solicitarla, a través de los mensajes, las cartas, los correos electrónicos, los mensajes de texto, por nombrar solo algunas. Así mismo, como instrumento de registro, que constituye una de las funciones más frecuentes y más cercanas de la escritura, mediante los mensajes y las razones que quedan a manera de "memoria" o de recordatorio (además de las tareas), pues la escritura guarda, preserva la memoria. Esta es una de las funciones que ha cumplido desde sus orígenes y se resalta su carácter de permanencia. Por último, los niños asocian la escritura con la posibilidad o la necesidad de trabajar. Ellos saben que sus padres y familiares adultos deben saber escribir para solicitar un trabajo y desempeñarse como profesionales.

Vista de esta manera, la escritura adquiere otro sentido para los niños, pues aunque saben que se requieren de un código alfabético para "armar" palabras, también han descubierto en las acciones diarias que la escritura favorece construcciones sociales y culturales. Es esta representación social la que se debe aprovechar dentro de la escuela. 
Durante el proceso de codificación axial de la teoría fundamentada, fueron surgiendo otros hallazgos de la investigación que es importante presentar a continuación:

- Las estrategias de enseñanza de los maestros se fundamentan en sus concepciones de escritura, pero difieren de su discurso. Aunque los docentes hayan sido formados desde un enfoque pedagógico determinado y aunque conozcan un discurso teórico o asistan a jornadas de actualización, en el momento de actuar en el aula y de enseñar la escritura recurren a su marco de referencia, es decir, a las concepciones construidas a lo largo de su experiencia docente e incluso personal, con todos los elementos que contienen y que les brindan confianza para enfrentar las situaciones nuevas que se les presentan en el aula.

Los profesores participantes en este proyecto tienen, en su mayoría, más de quince años de experiencia y han estado concibiendo formas de enseñar la escritura que se mueven entre lo alfabético, fuertemente arraigado, y el reconocimiento de posibilidades o indicios de transformación, que por ahora solo hacen parte de su discurso. La concepción alfabética de la escritura predomina porque los hace sentirse más "cómodos", porque mediante ella pueden ejercer mayor control frente a lo que van "adquiriendo" los niños, porque pueden evaluar el aprendizaje de las letras, la concordancia grafía-sonido, al aspecto motriz o el manejo del espacio. Es en este aspecto que las actividades más conocidas en su propia formación y experiencia funcionan: la copia, el dictado, la identificación de vocales y consonantes, la conformación de frases, etc. Se mantienen, además, las estrategias de fortalecimiento del ejercicio motriz de la escritura, como las planas, métodos de escritura establecidos que fomentan el aprendizaje del alfabeto, guías, actividades de aprestamiento, identificación de vocales iniciales de un dibujo o realización de pequeñas planas en cuadernos, hojas o textos, etc.

Sin embargo, los profesores en su discurso hacen referencia a temas pedagógicos "actuales" que invitan a implementar otras maneras de enseñar o de generar la construcción de la escritura (el trabajo por proyectos, por ejemplo). Ello deja ver que hay un conocimiento al respecto, ya sea como resultado de las capacitaciones o incluso de los estudios de posgrado en carreras relacionadas con la escritura (seis de los doce profesores manifestaron haber realizado especializaciones o maestrías). Pero dicho conocimiento no es una garantía para la transformación de sus concepciones de la escritura, a menos que estas se hagan conscientes y se favorezca su estudio, investigación y reflexión. De este modo se constituirían en un insumo para la transformación efectiva de las prácticas de enseñanza. Si este nuevo conocimiento no ha sido elaborado ni comprendido por los docentes, no logrará modificar ni creencias, ni ideas, ni supuestos. Lo que se presenta entonces es una contradicción entre prácticas y discursos. En el discurso, pareciera que los nuevos conocimientos teóricos son entendidos e incluso compartidos, pero no realmente elaborados, por lo que no logran modificar las concepciones y tampoco las prácticas.

En este punto es necesario preguntarse si los procesos de formación docente en las universidades, escuelas normales e institutos de educación superior están reconociendo las concepciones de los profesores (en ejercicio y en formación) como un elemento que requiere ser estudiado y analizado para generar cambios sustanciales en las maneras de entender la educación, los procesos de enseñanza y el quehacer en el aula. En 
todos estos elementos radica la importancia de las concepciones en la transformación de las prácticas de enseñanza y en la necesidad de volverlas objetos de investigación de los propios profesores y de las mismas instituciones. Al trasladar las concepciones al ámbito de investigación sobre la docencia, el conocimiento de los profesores se construye, se desarrolla y se organiza en un nivel diferente al de las especulaciones y supuestos (Arbeláez, 2004).

- Los profesores que enseñan a escribir no escriben. Además de la persistencia de las concepciones alfabética, perceptiva y motriz de la escritura en los profesores, otra de las razones por las cuales los docentes no logran concebir la escritura como un proceso transformador, social y cultural es el hecho de que ellos, que son quienes enseñan a escribir, no escriben. Para estos docentes la escritura solo se constituye en una herramienta de registro de la información; en un instrumento para la elaboración de guías, evaluaciones, informes de notas, planeaciones, etc. Esto es consecuente con la concepción instrumental de la escritura que también se evidencia en sus prácticas, que se aleja cada vez más de la posibilidad de comprenderla desde su carácter epistémico, como proceso complejo que favorece la construcción de conocimiento, o como objeto de desarrollo social y cultural que responde a objetivos o funciones claras y se vuelve un objeto de conocimiento para otros.

Al no asumirla de esta manera, los profesores no se constituyen en modelos de escritores para sus estudiantes ni para las instituciones en las que enseñan. No se conciben a sí mismos como escritores. No sienten la necesidad de comunicar, expresar o construir conocimiento por medio de la escritura, ni con sus colegas ni mucho menos con los estudiantes. Gran parte de los docentes no comprenden la escritura como un proceso que necesita las voces de otros, que tiene un propósito y que es precisamente desde los otros, como lectores, que adquiere sentido. Los docentes como profesionales de la educación deberían asumir la escritura como una actividad inherente a la construcción de conocimiento de todo tipo, incluso social, y de esta manera cualificarse y posibilitar otras maneras de enseñar en los primeros niveles de escolaridad, donde se privilegie y se considere toda su complejidad.

- La escritura no se asume como proceso de producción sistémico sino como proceso de adquisición del código alfabético. La respuesta más común que los profesores dieron frente a la pregunta sobre qué es la escritura fue la de señalar que es un proceso. Pero esta respuesta tan frecuente tiene un trasfondo. A partir de las acciones de los docentes tiene una acepción particular y no hace referencia a las etapas de planeación, revisión y reescritura propuestas por Flower y Hayes (1980, 1981, como se citan en Cassany, Luna y Sanz, 1997), ni a la secuencia de etapas propuestas por Ferreiro y Teberosky (1999), sino a las etapas en la enseñanza-adquisición del alfabeto: primero las vocales, luego las consonantes más comunes, las sílabas trabadas, la conformación de palabras, después las frases y, finalmente, los párrafos y textos más extensos.

Algunas profesoras, especialmente de preescolar, hicieron referencia a la necesidad de que los niños pasen por los diferentes momentos de la escritura: garabateo, presilábica, silábica, silábica alfabética y alfabética, pero las actividades que se observaron en el aula, o las que ellas mismas expresaron, son las tradicionales de copia, decorado de letras o trabajo en guías, que siempre favorecen el conocimiento de las letras. No se hizo referencia al propósito de 
reconocer el proceso particular que cada niño va teniendo en su propia construcción de la escritura, para fortalecer siempre una zona de desarrollo proximal, aprovechando la función social que cumple la escritura para promover su desarrollo. Es importante, entonces, aclarar que el término proceso de escritura también tiene acepciones diferentes, dependiendo de la concepción que haya construido un profesor. Este asunto debe discutirse y analizarse como parte de las investigaciones que busquen la transformación de la enseñanza de la escritura.

La escritura ha sido concebida desde diversas voces como un instrumento del pensamiento, como un elemento con función epistémica, que busca convertirse en una herramienta para desarrollar el propio pensamiento y transformar el conocimiento (Castelló, 2000; Jurado y Bustamante, 1996). Pero antes de comprenderla desde la perspectiva cognitiva y desde su función epistémica, es necesario recordar que la escritura es una construcción social y cultural. Este punto de vista no pretende reducirla a un instrumento funcional. Se trata de abrir espacios para reflexionar sobre cuál es el sentido de escribir y de enseñarles a escribir a los niños, entendiéndola como un proceso complejo que, si bien requiere aspectos formales y cognitivos, también necesita tener en cuenta aspectos sociales y culturales que forman parte de la vida de los niños como sujetos de una comunidad.

Se concluye que las concepciones de escritura que tengan los docentes pueden fortalecer o limitar el reconocimiento de las representaciones sociales de los niños en su propia construcción. Una concepción de escritura basada en la reflexión sobre la práctica, en la investigación y en el reconocimiento de los otros, niños y profesores, propiciará las construcciones sociales de los niños, no solo por las posibilidades ricas y valiosas que brinde en el aula, sino porque los asumirá como pares con los que se puede intercambiar conocimiento.
Mientras los docentes no logren transformar sus concepciones para promover la comprensión de la escritura como un proceso de desarrollo del pensamiento y de conocimiento social y cultural, tampoco será posible transformar las prácticas ni lograr los resultados esperados en los niños que están aprendiendo a escribir. Solo si los docentes son conscientes de sus propias maneras de concebir la escritura, pueden transformar sus prácticas en el espacio educativo.

Modificar las concepciones de los docentes requiere un trabajo de formación y de investigación constante, en el que son fundamentales la reflexión sobre la práctica y el estudio crítico de la teoría por parte de los maestros, ya que la sola información o "capacitación" no es suficiente. En este proceso es vital que los propios maestros se reconozcan como profesionales reflexivos y críticos frente a la tarea de educar, como actores sociales importantes y como agentes de transformación de la educación De no lograr este cambio, se seguirán reproduciendo en el aula las maneras tradicionales de enseñar la escritura y se seguirá concibiendo al maestro como administrador y ejecutor de acciones diseñadas por otros profesionales externos a la comunidad escolar.

Las concepciones de la escritura de los docentes y las representaciones sociales de escritura de los niños son elementos que, aunque forman parte de la vida del aula, no se reconocen ni se articulan para posibilitar la construcción de la escritura como un conocimiento social y cultural. Por el contrario, las concepciones de los docentes, al no reconocer las representaciones sociales de los niños, han propiciado que ellos tengan una manera de representarse la escritura dentro de la escuela y otra fuera de ella. El reconocimiento de las representaciones sociales de escritura de los niños permite a la vez concebirlos como sujetos de conocimiento que hacen parte importante de una sociedad y una cultura. 
La escuela debe, entonces, transformarse en un contexto complejo, rico y diverso en experiencias sustentadas en la vivencia misma de la escritura, en las que esta se desarrolle no solo en las aulas sino en otros espacios que puedan ser conquistados por los niños a través de la construcción individual o colectiva, de modo que el poder de la palabra escrita logre generar mundos posibles.

\section{Reconocimientos}

Este artículo es el resultado de investigación "La construcción de la escritura en el primer ciclo: entre las concepciones de los docentes y las representaciones sociales de los niños", realizada en el marco de la Maestría en Pedagogía en Lengua Materna, de la Universidad Distrital Francisco José de Caldas.

\section{Referencias}

Arbeláez, R. (2004). De los conceptos a las concepciones docentes. En Concepciones sobre una docencia universitaria de calidad. Estudio diferencial entre universidades y profesores. Tesis de doctorado sin publicar, Facultad de Filosofía y Ciencias de la Educación, Departamento de Didáctica y Organización Escolar, Universidad de Valencia, España.

Bruner, J. (1997). La educación puerta de la cultura. Madrid: Visor.

Cassany, D., Luna, M. y Sanz, G. (1997). Enseñarlengua. Barcelona: Graó.

Castelló, M. (2000). Las concepciones de los estudiantes sobre la escritura académica. En: A. Camps y M. Milian (comps.). El papel de la actividad metalingüística en el aprendizaje de la escritura (pp. 67-104) Rosario: Homo Sapiens.

Castorina, J. A. y Kaplan, C. (2003). Las representaciones sociales: problemas teóricos y desafíos educativos. En J. A. Castorina (comp.), Representaciones sociales: problemas teóricos y conocimientos infantiles (pp. 9-27). Barcelona: Gedisa.

Ferreiro, E. y Teberosky, A. (1999). Los sistemas de escritura en el desarrollo del niño. México: Siglo XXI.

Hernández, R., Fernández, C. y Baptista, P. (2008). Metodología de la investigación. México: McGraw Hill.

Jodelet, D. (1986). La representación social: fenómenos, concepto y teoría. En S. Moscovici (ed.), Psicología social II. Barcelona : Paidós. pp. 469-494.

Jodelet, D. y Guerrero, A. (2000). Develando la cultura. Estudios en representaciones sociales. México: Universidad Nacional Autónoma de México, Facultad de Psicología.

Jurado, F. y Bustamante, G. (1996). Los procesos de la escritura, hacia la producción interactiva de los sentidos. Bogotá: Magisterio.

Marcelo, C. (1987). El pensamiento del profesor. Barcelona: CEAC.

Moll, L. (Comp.). (1993). Vygotsky y la educación, connotaciones y aplicaciones de la psicología sociohistórica en la educación. Buenos Aires: Grupo Editor.

Morales, R. y Bojacá, B. (2002). ¿Qué hacemos los maestros cuando hablamos en el aula? Concepciones sobre la enseñanza de la lengua. Bogotá: Universidad Distrital Francisco José de Caldas y Colciencias.

Perafán, G. A. (2004). La epistemología del profesor sobre su propio conocimiento profesional. Bogotá: Universidad Pedagógica Nacional. 
Pittard, V. y Martlew, M. (2000). La cognición situada socialmente y la actividad metalingüística. En M. Milian y A. Camps (eds.), El papel de la actividad metalingüistica en el aprendizaje de la escritura (pp. 105-134). Rosario: Homo Sapiens.

Porlán, R. y Rivero, A. (1998). El conocimiento de los profesores. Sevilla: Díada.

Ramírez, P. y Gómez, J. H. (2000). La representación infantil del mundo social en el aula de clase. Las nociones sociales. Bogotá: Universidad Distrital Francisco José de Caldas, Instituto de Estudios e Investigaciones Educativas.
Strauss, A. y Corbin, J. (2002). Bases de la investigación cualitativa. Técnicas y procedimientos para desarrollar la teoría fundamentada. Medellín: Universidad de Antioquia.

Tolchinsky, L. (1993). Aprendizaje del lenguaje escrito. Barcelona: Anthropos.

Vygotsky, L. S. (1979). El desarrollo de los procesos psicológicos superiores. Buenos Aires: Grijalbo.

Vygotsky, L. S. (1931). La prehistoria del desarrollo del lenguaje escrito. En L. S. Vygotsky, L. S. (1995). Obras escogidas (t. III). Madrid: Visor. 